\title{
A Novel Study on The Effects of Minimum Quantity Lubrication and Machining Parameters in Turning of Ti-6Al-4V Alloy By Applying Al203-Graphene Hybrid Nanoparticle Enriched Cutting Fluid
}

\author{
Kashif Riaz Wattoo ( $\nabla$ eng.kr786@gmail.com ) \\ Institute of Space Technology \\ Muhammad Zubair Khan \\ Institute of Space Technology \\ Asif Israr \\ Institute of Space Technology \\ Muhammad Amin \\ Institute of Space Technology
}

\section{Research Article}

Keywords: Machining, Al-GnP hybrid, nanofluids, MQL, Soybean oil

Posted Date: February 15th, 2021

DOl: https://doi.org/10.21203/rs.3.rs-181678/v1

License: (c) (1) This work is licensed under a Creative Commons Attribution 4.0 International License.

Read Full License 


\section{Abstract}

In Minimum Quantity Lubrication (MQL) very small amount of cutting fluids are used. Currently, nanoparticles are added into cutting fluids to magnify the cooling and lubricating properties. Several studies are available on MQL to check the machining performance in terms of cooling and lubrication using nanofluids like $\mathrm{Ag}, \mathrm{SiO}_{2}, \mathrm{MoS}_{2}, \mathrm{Al}_{2} \mathrm{O}_{3}$, Cu and MWCNT. However, limited evidences are available in applying hybrid nanoparticles in machining processes. Present research investigates the effect of hybridization of two different nanofluids on machining performance in turning operation of Ti-6Al-4V alloy. Moreover, machineability was evaluated and analyzed by performing turning using minimum quantity lubrication (MQL) cooling technique. Cutting temperature and surface roughness of machined surface were taken as technological performance parameters to evaluate the machinability of Ti-6Al-4V alloy. Hybridization was performed by mixing alumina based nanofluid into graphene nanoparticles in a fixed volumetric proportion 80:20 using vegetable oil as base fluid. Additionally, machining performance was evaluated by preparing hybrid nanofluid in different concentrations like $(0.25,0.50,0.75$ and $1.00 \mathrm{vol} \%)$ and tested for thermophysical properties before experimentation. Significant improvements in thermophysical properties were observed during hybridization of $\mathrm{Al}_{2} \mathrm{O}_{3}$ and Graphene. For parametric optimization and design of experiment, Taguchi orthogonal array has been employed. Machining performance of vegetable oil base alumina-graphene hybrid nanofluid was compared with monotype alumina based nanofluid and a significant reduction cutting temperature and surface roughness was observed respectively.

\section{Introduction}

In manufacturing industry during machining of metals especially machining of super alloys large amount of heat is generated at the machining zone due to friction between tool tip and workpiece interface. This generated heat has lot of negative thermal effects So, cutting fluids are used to reduce the friction between tool tip and the workpiece by providing efficient lubricity and cooling during machining operations. Cutting fluids are used to reduce the negative thermal effects and chips are washed away from the machining zone. However, when cutting fluids are used in excessive amount it causes environmental pollution and effects the workers' health. Therefor dry machining could be the alternative option to restrict the excessive usage of cutting fluids. Krolczyk et al. and Grzesik et al[1, 2] have adopted dry machining and observed encouraging results regarding machining performance.

However dry machining is suitable at low cutting speed and preferred for easily machinable materials. Dry machining is not preferred at high depth of cutting and high-speed machining of super alloys because during dry machining of superalloys build up edges are produced on tool which reduced the tool life and effects the dimensional accuracy of the workpiece [3] Therefor to reduce the consumption of cutting fluids and negative effects of dry machining a novel technique MQL can be chosen.

Minimum Quantity Lubrication (MQL) also known as near dry machining (NDM). In this technique minimum amount of any cutting fluid is sprayed optimally into the cutting zone at high pressure for 
better penetration into the machining zone and improve tool chip interaction. Reddy et al.[4] studied the machining performance of MQL and the results were compared with dry machining and concluded that machining temperature, surface roughness, tool wear and the cutting forces were reduced significantly as compared to dry machining. Padmini et al.[5] observed the machining performance using MQL and concluded that lower cutting forces and tool wear were produced as compared to dry machining. Khan et al.[6] studied the machining performance using MQL and compared the results with flood cooling and concluded that by using MQL machining temperature was reduced by $10 \%$ and tool wear, surface roughness was also reduced.

Meanwhile, Maruda et al.[7] evaluated the machining performance using MQL turning of AISI 1045 carbon steel they observed a significant reduction of $40 \%$ in tool wear compared to dry machining. Maruda et al.[8] studied the machining performance of MQL and observed that by using MQL surface roughness of machined stainless steel was reduced more than three times as compared to dry machining. Behera et al.[9] proposed a model for local coefficient of friction as a function of MQL parameters and cutting conditions that predicts cutting forces, contact length and chip thickness under MQL environment.

Furthermore, Singh et al. [10] and Kishawy et al. [11] studied the machining performance using MQL and concluded that using MQL technique surface finish and tool life improved and machining temperature, cutting forces are reduced. Ganguli et al. [12] investigated the machining performance of Automized cutting fluid spray system during machining of Titanium Alloy. They concluded that lower cutting forces, lower surface roughness and observed enhancement of tool life as compared to wet machining. In their opinion MQL might be a viable alternate to dry and wet machining. Therefor MQL can minimize the machining cost without effecting the machining performance, by restricting the excessive use of cutting fluids and environmental hazards.

The conventional cutting fluids possess good lubrication properties but limited cooling properties due to poor thermal conductivity associated with them, restrict their use as cutting fluid during high speed machining of super alloys. To overcome this problem nanofluids are used, nanofluids are suspension of nanometer size particles into conventional cutting fluids or vegetable oil, which leads to improve heat extraction rate from machining zone due to enhanced thermal conductivity [13].

Sen Gupta et al. [14] observed in their researches that by adding nanoparticles into conventional cutting fluids enhanced their thermal conductivity compare to base fluids. An improvement up to $22.4 \%$ in thermal conductivity of conventional fluid at room temperature could be achieved by adding $6 \% \mathrm{Al}_{2} \mathrm{O}_{3}$ at room temperature. Esfe et al. [15] developed the Al2O3 ethylene glycol based nanofluid and studied the effect of temperature and Al2O3 nanoparticles on thermal conductivity. They observed significant enhancement in thermal conductivity with the increase in concentration and temperature. Choi et al. [16] prepared the nanofluid by mixing multi walled carbon nanotubes [MWCNT] into base fluid and observed significant improvement in its thermal conductivity up to $200 \%$ and $150 \%$ respectively compared to its base fluid. 
Ghosh et al. [17] prepared the nanofluid by mixing $\mathrm{Al}_{2} \mathrm{O}_{3}$ and MWCNT separately into base fluid and evaluated the machining performance during high speed turning of steel using MQL. They concluded that nanofluid containing MWCNT nanoparticles have better lubricity and cooling effect as compared to $\mathrm{Al}_{2} \mathrm{O}_{3}$ nanoparticles. Saravana Kumar et al. [18] evaluated the machining performance of MQL by using Ag nanoparticles. Turning operation was performed at different cutting speed and depth of cut using nanofluid containing Ag nanoparticles and compared the results with conventional fluid cooling and concluded that cutting forces and surface roughness was reduced to $8.8 \%$ and $7.5 \%$ with the use of nanofluid.

MingLi et al. [19] evaluated the machining performance of Graphene nanoparticles enriched cutting fluid in milling operation and observed significant reduction in cutting forces and cutting temperature up to $18.13 \%$ and $13.59 \%$ respectively. Sirikant et al. [20] achieved a significant reduction of $71 \%$ and $25 \%$ in tool wear and machining temperature with the use of nanofluid containing graphite nanoparticles in MQL Turning compare to conventional flood machining. Krishna et al. [21] prepared the nanofluid by using boric acid in coconut oil and evaluated the machining performance during MQL Turning of AISI 1040 steel and achieved a significant reduction in cutting temperature, surface roughness and tool wear.

Sharma et al. [22] prepared the nanofluid by mixing $\mathrm{TiO}_{2}$ nanoparticles in DI water and evaluated the machining performance during Turning operation and observed enhance machining performance over conventional flood cooling. Sidik et al. [23] reviewed the research work carried out in various research works based on application of $\mathrm{Al}_{2} \mathrm{O}_{3}, \mathrm{CNT}, \mathrm{MoS}_{2}$ and diamond nanoparticles with MQL in machining operations. They observed that significant improvement could be achieved in all researches.

Many researches have been conducted in manufacturing processes with cutting fluids containing mono type of nanoparticles. However, to the best of author's knowledge very few researches have been carried out in machining using nanofluids containing hybrid nanoparticles (i.e. a colloidal suspension having two different type of nanoparticles ) Sarkar and Gosh [24] reviewed the research works available on hybrid nanofluids and observed that proper hybridization might be helpful in making hybrid nanofluids very useful for heat transfer enhancement in machining processes and other heat transfer applications. Suresh et al. [25] prepared the water-based hybrid nanofluid containing Al2O3 and Cu nanoparticles made it a potential heat transfer fluid. Tansen et. al [26] prepared the Nano cutting fluid enriched with MWCNT and alumina, yielded superior machining performance compared to single nanoparticle enriched cutting fluid. Nine et al. [27] prepared a nanofluid containing MWCNT and alumina nanoparticles and observed significant enhancement in thermal conductivity compared to nanofluid containing single nanoparticle.

Furthermore, Zhang et al. [28] evaluated the machining performance of Al203-SiC enriched hybrid nanofluid and concluded that hybrid nanofluid yielded better surface quality compared to mono type nanofluid. Moreover, Ahammad et al. [29] prepare the alumina-graphene enriched hybrid nanofluid and achieved $88.62 \%$ enhancement in convective heat transfer and a reduction of $4.7^{\circ} \mathrm{C}$ in cutting tool temperature. Zhang et al. [30] prepared the MoS2-CNT enriched hybrid nanofluid and evaluated 
machining performance by MQL grinding operation and achieved lower $\mathrm{G}$ ratio and surface roughness ( $\mathrm{Ra}=0.328 \mathrm{um}$ ) compared to mono type nanofluid of $\mathrm{MoS}_{2}$ and CNT.

Moreover, few researches have been conducted on enhancement in thermophysical properties [31] and Tribological properties [32] of base nanofluids by using different types of nanoparticles. However, not much significant work could be reported in the available literature regarding the application of hybrid nanofluids in manufacturing processes, especially in milling operation.

In the present research, the $\mathrm{Al}_{2} \mathrm{O}_{3}$-Graphene enriched hybrid nanofluid is prepared by mixing Aluminum and Graphene nanoparticles in a fixed volumetric proportion of (80:20) at different nanoparticles fractions $(0.25,0.5,0.75$ and $1.00 \mathrm{vol} . \%)$ and soybean oil is used as base fluid. All the developed nanofluids samples are tested for their thermophysical properties namely thermal conductivity at different temperatures. Later the machining performance of $\mathrm{Al}_{2} \mathrm{O}_{3}$-Graphene enriched hybrid nanofluid is evaluated during MQL Turning of Ti-6Al-4V alloy and compared in terms of machining temperature and surface roughness with the results of dry machining and monotype alumina based nanofluid.

\section{Experimentation}

The Turning of Ti-6Al-4V was carried out using MQL technique under the mist having different concentrations of $\mathrm{Al}_{2} \mathrm{O}_{3}$-Graphene enriched nanofluid. However, the nanofluid samples having various concentration were prepared and tested for their thermophysical properties, before machining.

\subsection{Nano Cutting fluids: Preparation and Characterization}

The nanofluids were prepared by dispersing various concentration of $\mathrm{Al}_{2} \mathrm{O}_{3}$ and graphene in soybean oil. To make homogeneous mixture of hybrid nanoparticles and soybean oil the cutting fluids were first stirred using a magnetic stirrer (for 40 mins) and then dispersed using an ultrasonic dispersion instrument (for $3 \mathrm{~h}$ ) shown in fig. 1

This process repeated several times until the nanoparticles were uniformly dispersed in soybean oil. The $\mathrm{Al}_{2} \mathrm{O}_{3}$-Graphene enriched cutting fluids were stable and no agglomeration was observed during the entire experimentation process. A fresh sample of nanofluid was developed for each experiment and used immediately to avoid possible sedimentation/agglomeration of nanoparticles. The nanofluids were tested for thermal stability at various temperatures. Moreover, the effect of nanoparticles concentration on its thermophysical properties and heat transfer enhancement was investigated. The $\mathrm{Al}_{2} \mathrm{O}_{3}$-Graphene hybrid nanofluid shows an enhancement of $9.8 \%$ in thermal conductivity and thermal stability also improved [33]. Furthermore, with the rise in temperature all samples of $\mathrm{Al}_{2} \mathrm{O}_{3}$-Graphene enriched nanofluids showed reduction in viscosity [34].

Moreover, with the increment in volumetric concentration ( $0.25,0.5,0.75$ and 1.00 etc.) vol\% of nanoparticles with $\mathrm{Al}_{2} \mathrm{O}_{3}$-graphene hybrid nanofluid increment in viscosity also occurs. Investigations 
reveal that with the rise in nanoparticles volumetric concentration increase both the thermophysical properties and viscosity. The increment in thermal conductivity affects the machining performance positively due to enhancement in heat transfer from machining zone to the cutting fluid provide cooling and lubrication to the tool workpiece interface, while higher viscosity causes a problem (pressure drop) in spraying mist of Nano lubricants to the machining zone with the MQL technique. To stabilize the advantages of greater thermal conductivity and disadvantages of higher viscosity (loss in pumping power), the authors selected the particle volumetric range from $0.25 \mathrm{vol} \%$ to $1.00 \mathrm{vol} \%$.

\subsection{Experimental Setup}

Turning of Ti-6Al-4V alloy was accomplished on Lathe machine (Institute of Space Technology, Pakistan) by applying aerosol of hybrid nano-cutting fluid using various concentrations of $\mathrm{Al}_{2} \mathrm{O}_{3}$ and Graphene nanoparticles under MQL technique. The experimental setup is shown in fig.4. The coated cemented carbide tool tip was used for experimentation. In addition, an Accu-Lube MQL system imported from China was used to applying the $\mathrm{Al}_{2} \mathrm{O}_{3}$-graphene dispersed cutting fluid to the cutting zone. This AccuLube MQL system consists of a pulse pump, air pump, pulse generator, filter, oil tank and oil gas mixing tube as shown in fig.4. The nano cutting fluid flow rate and air supply pressure is adjustable for this MQL system and nanofluid flow rate was set at $40 \mathrm{~mL} / \mathrm{h}$. A nozzle having $1 \mathrm{~mm}$ discharge dia. was used and set up $6 \mathrm{~cm}$ above the rake face of the cutting tool, capable of impinging aerosol vertically downward on the workpiece tool tip interface in order to provide efficient cooling and lubrication.

To evaluate the effects of MQL and machining parameters on machining performance during turning of Ti-6Al-4V alloy each experiment were performed in triplicate and taken average of the values. The Machining temperature $\mathrm{T}\left(\mathrm{C}^{0}\right)$ was measured with an Arduino based data acquisition system which includes $\mathrm{K}$ type thermocouple which was connected with an electrical circuit through MAX 6675. The electric circuit connects the sensors through MAX 6675, with an Arduino Mega 2560, which displays the thermocouple temperature readings through serial monitor in Arduino IDE. Thermocouple was inserted in to a $4 \mathrm{~mm}$ diameter hole in the tool tip (as shown in below fig.) to measure the surface temperature. Moreover, the average surface roughness $(\mathrm{Ra})$ was measured by 3D optical profiler, which can measure curved, flat or stepped, polished or rough surfaces efficiently.

\subsection{Selection of workpiece material and Tool}

In this research work Ti-6Al-4V alloy was used as workpiece material. The dimension of the workpiece was $40 \mathrm{~mm}$ in diameter and $0.61 \mathrm{~m}$ in length. Grinding process was used to remove the oxide layer from the workpiece material earlier to experimentation. Chemical composition and mechanical properties workpiece material are shown in table 1 and table 2 respectively

Table 1: Chemical composition of TC4 


\begin{tabular}{|lccc|}
\hline Element & $\mathrm{Ti}$ & $\mathrm{Al}$ & $\mathrm{V}$ \\
\hline Composition (wt.\%) & 91.56 & 5.35 & 3.08 \\
\hline
\end{tabular}

Table 2: Mechanical properties of TC4

\begin{tabular}{|c|c|c|c|c|c|}
\hline Property & Tensile strength & Yield strength & Elongation & Hardness & Modulus of \\
\hline & (MPa) & (MPa) & $\%$ & $(\mathrm{HV})$ & elasticity (GPa) \\
\hline Value & 990 & 830 & 14 & 312 & 114 \\
\hline
\end{tabular}

Additionally, due to large coefficient of friction, low thermal conductivity, and high chemical reactivity Ti$6 \mathrm{Al}-4 \mathrm{~V}$ alloy is difficult to machine and high heat generation occurs. So, coated cemented carbide insert clamped by a screw on a rigid tool holder was used as a cutting tool. It is perfect due to its high toughness, high wear resistance and low chemical reactivity for machining Ti-6Al-4V alloys. Ghani et al. [35] Therefore, coated cemented carbide tool was adopted in this research work.

\subsection{Experimental Design}

The technique of investigation and defining all possible conditions in experimentation, involving various factors is known as design of experiments (DOE). Taguchi method was selected to design the experimental array $L_{16}\left(4^{3}\right) O A$ in order to minimize the machining temperature, and surface roughness. The standard OA consist of 16 experiments with four control factors and four experimental state levels for each control factor. The parameters such as nanoparticles concentration, air pressure, cutting speed and depth of cut were chosen as control factors and machining characteristics such as cutting temperature and surface roughness were recognized as response factors. The detail of experimental conditions for each control factors and orthogonal array are shown in table 5 and table 6 . In order to remove any other invisible factors that may also affect the cutting temperature and surface roughness all the experiments were performed randomly.

Table 3: Control factors and experimental levels

\begin{tabular}{|lccccccc|}
\hline Control Factors & \multicolumn{2}{c}{ Symbols } & Units & Level $_{1}$ & Level $_{2}$ & Level $_{3}$ & Level $_{4}$ \\
\hline Nanoparticle concentration & W & vol.\% & 0.25 & 0.50 & 0.75 & 1.00 \\
\hline Air Pressure & $\mathrm{P}$ & $\mathrm{MPa}$ & 0.3 & 0.4 & 0.5 & 0.6 \\
\hline Cutting Speed & $\mathrm{v}$ & $\mathrm{mm} / \mathrm{min}$ & 470 & 870 & 1270 & 1670 \\
\hline Depth of Cut & $\mathrm{d}$ & $\mathrm{mm}$ & 1.2 & 1.4 & 1.6 & 1.8 \\
\hline
\end{tabular}


Table 4: Standard $\mathrm{L}_{16}(4)^{3}$ Orthogonal Array

\begin{tabular}{|c|c|c|c|c|}
\hline \multirow[t]{2}{*}{ Experiment no. } & \multicolumn{4}{|c|}{$\begin{array}{l}\text { Control factors and } \\
\text { Experiment levels }\end{array}$} \\
\hline & w & $p$ & $v$ & $d$ \\
\hline 1 & 1 & 1 & 1 & 1 \\
\hline 2 & 1 & 2 & 2 & 2 \\
\hline 3 & 1 & 3 & 3 & 3 \\
\hline 4 & 1 & 4 & 4 & 4 \\
\hline 5 & 2 & 1 & 2 & 3 \\
\hline 6 & 2 & 2 & 1 & 4 \\
\hline 7 & 2 & 3 & 4 & 1 \\
\hline 8 & 2 & 4 & 3 & 2 \\
\hline 9 & 3 & 1 & 3 & 4 \\
\hline 10 & 3 & 2 & 4 & 3 \\
\hline 11 & 3 & 3 & 1 & 2 \\
\hline 12 & 3 & 4 & 2 & 1 \\
\hline 13 & 4 & 1 & 4 & 2 \\
\hline 14 & 4 & 2 & 3 & 1 \\
\hline 15 & 4 & 3 & 2 & 4 \\
\hline 16 & 4 & 4 & 1 & 3 \\
\hline
\end{tabular}

\section{Results And Discussion}

Turning operation on Ti-6Al-4V was performed as per experimental design by varying the MQL and machining parameters such as concentration of nanoparticles, air pressure, cutting speed and depth of cut to evaluate the machining performance in terms of machining temperature and surface roughness using alumina based nanofluid and Al-GnP hybrid cutting fluid.

Table 5: Orthogonal array and experimental results for Cutting temperature Tc and Surface roughness Ra 


\begin{tabular}{|c|c|c|c|c|c|c|c|c|}
\hline \multirow[t]{3}{*}{ No. } & \multicolumn{4}{|c|}{ MQL Parameters } & \multicolumn{4}{|c|}{ Response Parameters } \\
\hline & \multirow[b]{2}{*}{ W } & \multirow[b]{2}{*}{$P$} & \multirow[b]{2}{*}{ v } & \multirow[b]{2}{*}{$d$} & \multicolumn{2}{|c|}{$\mathrm{Al}_{2} \mathrm{O}_{3}$ nanofluid } & \multicolumn{2}{|c|}{ Al-GnP Hybrid nanofluid } \\
\hline & & & & & $\mathrm{T}^{0} \mathrm{C}$ & $\mathrm{Ra}(\mu \mathrm{m})$ & $\mathrm{T}^{0} \mathrm{C}$ & $\mathrm{Ra}(\mu \mathrm{m})$ \\
\hline 1 & 0.25 & 0.3 & 470 & 1.2 & 245.77 & 2.813 & 205.66 & 1.913 \\
\hline 2 & 0.25 & 0.4 & 870 & 1.4 & 228.86 & 2.468 & 188.85 & 1.568 \\
\hline 3 & 0.25 & 0.5 & 1270 & 1.6 & 197.76 & 1.575 & 157.77 & 0.775 \\
\hline 4 & 0.25 & 0.6 & 1670 & 1.8 & 238.99 & 2.335 & 198.99 & 1.435 \\
\hline 5 & 0.50 & 0.3 & 870 & 1.6 & 184.78 & 1.999 & 144.78 & 1.099 \\
\hline 6 & 0.50 & 0.4 & 470 & 1.8 & 196.24 & 2.557 & 156.24 & 1.657 \\
\hline 7 & 0.50 & 0.5 & 1670 & 1.2 & 176.34 & 1.924 & 136.34 & 1.024 \\
\hline 8 & 0.50 & 0.6 & 1270 & 1.4 & 200.76 & 1.669 & 160.76 & 0.770 \\
\hline 9 & 0.75 & 0.3 & 1270 & 1.8 & 202.78 & 1.757 & 162.78 & 0.857 \\
\hline 10 & 0.75 & 0.4 & 1670 & 1.6 & 198.56 & 1.925 & 158.56 & 1.025 \\
\hline 11 & 0.75 & 0.5 & 470 & 1.4 & 211.26 & 1.985 & 170.26 & 1.085 \\
\hline 12 & 0.75 & 0.6 & 870 & 1.2 & 232.21 & 1.957 & 192.21 & 1.057 \\
\hline 13 & 1.00 & 0.3 & 1670 & 1.4 & 234.46 & 2.001 & 194.66 & 1.101 \\
\hline 14 & 1.00 & 0.4 & 1270 & 1.2 & 197.27 & 2.011 & 157.27 & 1.111 \\
\hline 15 & 1.00 & 0.5 & 870 & 1.8 & 220.16 & 2.995 & 180.16 & 2.095 \\
\hline 16 & 1.00 & 0.6 & 470 & 1.6 & 241.25 & 1.998 & 201.25 & 1.098 \\
\hline
\end{tabular}

\subsection{Influence on cutting temperature}

A significant reduction in machining temperature was observed during the turning process of Ti-6Al-4V alloy by using Al-GnP hybrid cutting fluid over monotype alumina based cutting fluid. This is due to the greater thermophysical properties processed by Al-GnP hybrid cutting fluid compared to alumina mixed nanofluid [36]. Moreover, the attained results regarding thermophysical properties were found to be in good agreement with previous investigation [37]. They observed during their research work that graphene based cutting fluid could be used in high speed metal removal processes as potential heat transfer nanofluid. Moreover, they observed enough thermal conductivity enhancement up to $45.2 \%$ with graphene dispersed nanofluid over base fluid. 
It is concluded from the table 5 that concentration of Al-GnP nanoparticles (W) and its interaction with cutting speed and depth of cut (d) have prominent effect on the cutting temperature compared to air pressure $(P)$. The most significant parameter for the machining zone temperature was nanoparticles concentration. It was observed during experimentation that when the nanofluid concentration was increased from 0.25 vol.\% to 1.00 vol.\% machining temperature first increased and then decreased and when Al-GnP concentration was 1.00 vol.\% cutting temperature was again higher as shown in below graph. This is due to relatively large quantity of nanoparticles that blocked the machining zone and prevent the formation of oil film thereby weakening the rate of heat transfer from machining zone. Meanwhile, when the nanoparticles concentration was too low the cutting temperature was maximum as shown in table 5 due to less rate of heat transfer and insufficient cooling.

It was investigated that during the turning of Ti-6Al-4V alloy when the air pressure increased from $0.3 \mathrm{MPa}$ to $0.6 \mathrm{MPa}$ initially the cutting temperature was high however gradually decreased and was minimum at $0.5 \mathrm{vol} \%$ nanofluid concentration, $0.5 \mathrm{MPa}$ air pressure, $1670 \mathrm{~mm} / \mathrm{min}$ cutting speed and $1.2 \mathrm{~mm}$ depth of cut. The variation of milling temperature also shown in above graph (fig. 7) It is observed from the table 5 that there is significant \%age change in cutting temperature Tc while using Al-GnP hybrid nanofluid compared to monotype alumina based nanofluid.

So, the lower machining temperature was observed during turning operation of Ti-6Al-4V alloy by using Al-GnP hybrid nanofluid compared to monotype alumina based nanofluid due to greater thermophysical properties of hybrid nanofluid. It can be observed from the table 5 that the optimal values of MQL parameters for minimum milling temperature can be designed namely 0.5 vol.\% hybrid nanoparticles concentration $\mathrm{W}, 0.5 \mathrm{MPa}$ air pressure, $1670 \mathrm{~mm} / \mathrm{min}$ cutting speed and 1.2 depth of cut.

\subsection{Influence on surface roughness}

In the case of Al-GnP hybrid nanofluid coefficient of friction is reduced due to synergic effect, polishing and rolling effect so, the better surface quality was achieved compared to monotype type alumina enriched cutting fluid [38]. It was investigated during the turning of Ti alloy that air pressure P, depth of cut $d$, cutting speed $v$ and Al-GnP hybrid nanoparticles concentration significantly affect the surface roughness. Moreover, Al-GnP hybrid nanofluid concentration (W) and depth of cut (d) were the most significant parameter, followed by cutting speed $(v)$ and air pressure $(P)$.

Furthermore, during the turning operation of TC4 alloy when the concentration of alumina based nanofluid and Al-GnP hybrid nanofluid was increased from 0.25 vol.\% to 1.00 vol. \% initially surface roughness was higher but decreased gradually and was minimum at 0.50 vol.\% nanofluid concentration. However, if the concentration (W) increased further then surface roughness increased and reaching the maximum at 1.00 vol.\% nanofluid concentration as shown in table 5 and below graph as well.

Meanwhile, when the air pressure was increased from 0.3 MPa to $0.6 \mathrm{MPa}$ surface initially surface roughness was higher then gradually decreased and was minimum at $0.5 \mathrm{MPa}$. However, if the air pressure increased further then surface roughness increased again and was maximum at $0.6 \mathrm{MPa}$ as 
shown in table 5 . Similarly, when the cutting speed was $470 \mathrm{~mm} / \mathrm{min}$ the surface roughness was maximum and decreased gradually as the cutting speed increased, was minimum at $1670 \mathrm{~mm} / \mathrm{min}$ as shown in table 5. Moreover, when the depth of cut was higher the surface roughness was also higher while with the decrease in depth of cut the surface was also reduced and minimum at $1.2 \mathrm{~mm}$ depth of cut as shown in table 5.

So, optimal MQL parameters for milling of Ti-6Al-4V alloy namely 0.50 vol.\% concentration $\mathrm{W}$ of both monotype and hybrid nanofluid, $80 \mathrm{~mL} / \mathrm{h}$ flow rate $\mathrm{Q}$ and $0.5 \mathrm{MPa} \mathrm{P}$ air pressure. Overall, it could be concluded that cutting fluid concentration was the most significant MQL parameter affecting the milling characteristics rather than nanofluid flow rate and air pressure during the slot milling of Titanium alloy with monotype alumina based nanofluid and Al-GnP hybrid nanofluid using MQL technique.

\section{Conclusion}

Present study investigates the MQL (minimum quantity lubrication) machining performance of alumina vegetable oil based nanofluid and Al-GnP hybrid nanofluid through turning operation of TC4 alloy. The optimization of different control factors (nanofluid concentration W, Air pressure P, cutting speed v and depth of cut d) for response parameters such as machining temperature ( $T$ ) and surface roughness (Ra) using alumina vegetable oil based nanofluid and Al-GnP hybrid nanofluid. Before experiments the $\mathrm{Al}_{2} \mathrm{O}_{3}$ vegetable oil based nanofluid was mixed with Al-GnP hybrid nanofluid in a fixed volumetric ratio of 80:20. Meanwhile, SEM analysis of monotype type $\mathrm{Al}_{2} \mathrm{O}_{3}$ and graphene and their hybrid Al-GnP nanoparticles was performed to investigate the morphology, then machining performance was investigated through various MQL and machining parameters. Based on the results and discussion following conclusions could be made:

- Nanofluid concentration W, air pressure P, cutting speed v and depth of cut $d$ all have significant effect on machining temperature and surface roughness. However, nanofluid concentration for both the nanofluids (alumina and Al-GnP hybrid) is the most significant parameter that affect the cutting temperature because with the increase in nanoparticles concentration coefficient of friction is reduced giving efficient cooling and lubrication.

- The Al-GnP hybrid nanofluid has shown a prominent reduction in milling temperature from $176.341^{\circ} \mathrm{C}$ to $136.345^{\circ} \mathrm{C}$ compared to monotype alumina based nanofluid. Meanwhile nanofluid concentration significantly affect the milling temperature followed by air pressure and air pressure is not significant (table 5)

- With the use of Al-GnP hybrid nanofluid lower value of surface roughness has obtained. Moreover, nanofluid concentration, air pressure, cutting speed and depth of cut have significant effect on surface roughness. However, nanofluid concentration and depth of cut have greater effect on surface roughness followed by air pressure has least significant effect as shown in table 5.

- The Al-GnP hybrid vegetable oil based nanofluid is effective for improving machining performance compared to monotype alumina based nanofluid in terms of machining temperature and surface 
roughness through better cooling and lubrication.

- The improved thermophysical properties due to blending of two different nanofluids graphene with $\mathrm{Al}_{2} \mathrm{O}_{3}$ in fixed volumetric ratio $(80: 20)$ proved to be the effective lubricant. However, the optimization of mixing ratio may improve the performance of lubricant in heat transfer applications.

Most of the publish work on MQL have given more attention to nanofluids containing single nanoparticles in machining processes. In present work the researcher has investigated the hybridization of two different types of nanoparticles and evaluated the machining performance. The blending of alumina with graphene in a fixed volumetric ratio improved its thermophysical properties (heat transfer enhancement). However, optimization of mixing ratio may further improved machining performance. Meanwhile, the present work can further be extended by performing machining at different nanoparticles volumetric fraction their shape, size and employing different nanoparticles. This would be helpful in developing cutting fluids with improved thermophysical properties for the machining of metals and different alloys. Furthermore, with the usage of MQL technique and vegetable oil-based cutting fluids with improved thermophysical properties may reduce the machining cost with effecting the machining performance and environmental pollution.

\section{Declarations}

The authors declare that they have no known competing financial interests or personal relationships that could have appeared to influence the work reported in this paper.

The authors declare the following financial interests/personal relationships which may be considered as potential competing interests:

No declaration interests

\section{References}

1. G. Krolczyk, P. Nieslony, R. Maruda, and S. Wojciechowski, "Dry cutting effect in turning of a duplex stainless steel as a key factor in clean production," Journal of Cleaner Production, vol. 142, pp. 33433354, 2017.

2. W. Grzesik, P. Niesłony, W. Habrat, J. Sieniawski, and P. Laskowski, "Investigation of tool wear in the turning of Inconel 718 superalloy in terms of process performance and productivity enhancement," Tribology International, vol. 118, pp. 337-346, 2018.

3. A. E. Diniz and A. J. de Oliveira, "Optimizing the use of dry cutting in rough turning steel operations," International Journal of Machine Tools and Manufacture, vol. 44, pp. 1061-1067, 2004.

4. V. Vasu and G. Pradeep Kumar Reddy, "Effect of minimum quantity lubrication with Al2O3 nanoparticles on surface roughness, tool wear and temperature dissipation in machining Inconel 600 alloy," Proceedings of the Institution of Mechanical Engineers, Part N: Journal of Nanoengineering and Nanosystems, vol. 225, pp. 3-16, 2011.

Page $12 / 20$ 
5. R. Padmini, P. V. Krishna, and G. K. M. Rao, "Effectiveness of vegetable oil based nanofluids as potential cutting fluids in turning AISI 1040 steel," Tribology International, vol. 94, pp. 490-501, 2016.

6. M. Khan, M. Mithu, and N. R. Dhar, "Effects of minimum quantity lubrication on turning AISI 9310 alloy steel using vegetable oil-based cutting fluid," Journal of materials processing Technology, vol. 209, pp. 5573-5583, 2009.

7. R. W. Maruda, G. M. Krolczyk, E. Feldshtein, P. Nieslony, B. Tyliszczak, and F. Pusavec, "Tool wear characterizations in finish turning of AISI 1045 carbon steel for MQCL conditions," Wear, vol. 372, pp. 54-67, 2017.

8. R. Maruda, E. Feldshtein, S. Legutko, and G. Królczyk, "Improving the efficiency of running-in for a bronze-stainless steel friction pair," Journal of Friction and Wear, vol. 36, pp. 548-553, 2015.

9. B. C. Behera, S. Ghosh, and P. V. Rao, "Modeling of cutting force in MQL machining environment considering chip tool contact friction," Tribology International, vol. 117, pp. 283-295, 2018.

10. R. K. Singh, A. R. Dixit, A. Mandal, and A. K. Sharma, "Emerging application of nanoparticle-enriched cutting fluid in metal removal processes: a review," Journal of the Brazilian Society of Mechanical Sciences and Engineering, vol. 39, pp. 4677-4717, 2017/11/01 2017.

11. H. Kishawy, M. Dumitrescu, E.-G. Ng, and M. Elbestawi, "Effect of coolant strategy on tool performance, chip morphology and surface quality during high-speed machining of A356 aluminum alloy," International Journal of Machine Tools and Manufacture, vol. 45, pp. 219-227, 2005.

12. S. Ganguli and S. G. Kapoor, "Improving the performance of milling of titanium alloys using the atomization-based cutting fluid application system," Journal of Manufacturing Processes, vol. 23, pp. 29-36, 2016.

13. H. Salimi-Yasar, S. Z. Heris, and M. Shanbedi, "Influence of soluble oil-based TiO2 nanofluid on heat transfer performance of cutting fluid," Tribology International, vol. 112, pp. 147-154, 2017.

14. S. Sen Gupta, V. Manoj Siva, S. Krishnan, T. Sreeprasad, P. K. Singh, T. Pradeep, et al., "Thermal conductivity enhancement of nanofluids containing graphene nanosheets," Journal of Applied Physics, vol. 110, p. 084302, 2011.

15. M. H. Esfe, A. Karimipour, W.-M. Yan, M. Akbari, M. R. Safaei, and M. Dahari, "Experimental study on thermal conductivity of ethylene glycol based nanofluids containing Al203 nanoparticles," International Journal of Heat and Mass Transfer, vol. 88, pp. 728-734, 2015.

16. S. Choi, Z. Zhang, W. Yu, F. Lockwood, and E. Grulke, "Anomalous thermal conductivity enhancement in nanotube suspensions," Applied physics letters, vol. 79, pp. 2252-2254, 2001.

17. S. Roy and A. Ghosh, "High-speed turning of AISI 4140 steel by multi-layered TiN top-coated insert with minimum quantity lubrication technology and assessment of near tool-tip temperature using infrared thermography," Proceedings of the Institution of Mechanical Engineers, Part B: Journal of Engineering Manufacture, vol. 228, pp. 1058-1067, 2014.

18. N. Saravanakumar, L. Prabu, M. Karthik, and A. Rajamanickam, "Experimental analysis on cutting fluid dispersed with silver nano particles," Journal of Mechanical Science and Technology, vol. 28, pp. 645-651, 2014. 
19. M. Li, T. Yu, L. Yang, H. Li, R. Zhang, and W. Wang, "Parameter optimization during minimum quantity lubrication milling of TC4 alloy with graphene-dispersed vegetable-oil-based cutting fluid," Journal of cleaner production, vol. 209, pp. 1508-1522, 2019.

20. M. Amrita, R. Srikant, and A. Sitaramaraju, "Performance evaluation of nanographite-based cutting fluid in machining process," Materials and Manufacturing Processes, vol. 29, pp. 600-605, 2014.

21. R. Padmini, P. V. Krishna, and G. K. Mohana Rao, "Experimental evaluation of nano-molybdenum disulphide and nano-boric acid suspensions in vegetable oils as prospective cutting fluids during turning of AISI 1040 steel," Proceedings of the Institution of Mechanical Engineers, Part J: Journal of Engineering Tribology, vol. 230, pp. 493-505, 2016.

22. A. K. Sharma, A. K. Tiwari, and A. R. Dixit, "Progress of nanofluid application in machining: a review," Materials and Manufacturing Processes, vol. 30, pp. 813-828, 2015.

23. N. A. C. Sidik, S. Samion, J. Ghaderian, and M. N. A. W. M. Yazid, "Recent progress on the application of nanofluids in minimum quantity lubrication machining: A review," International Journal of Heat and Mass Transfer, vol. 108, pp. 79-89, 2017.

24. J. Sarkar, P. Ghosh, and A. Adil, "A review on hybrid nanofluids: recent research, development and applications," Renewable and Sustainable Energy Reviews, vol. 43, pp. 164-177, 2015.

25. S. Suresh, K. Venkitaraj, and P. Selvakumar, "Synthesis, Characterisation of Al203-Cu Nano composite powder and water based nanofluids," in Advanced Materials Research, 2011, pp. 15601567.

26. M. R. Tanshen, S. Lee, J. Kim, D. Kang, J. Noh, H. Chung, et al., "Pressure distribution inside oscillating heat pipe charged with aqueous Al 203 nanoparticles, MWCNTs and their hybrid," Journal of Central South University, vol. 21, pp. 2341-2348, 2014.

27. M. J. Nine, M. Batmunkh, J.-H. Kim, H.-S. Chung, and H.-M. Jeong, "Investigation of Al2O3-MWCNTs hybrid dispersion in water and their thermal characterization," Journal of nanoscience and nanotechnology, vol. 12, pp. 4553-4559, 2012.

28. X. Zhang, C. Li, Y. Zhang, D. Jia, B. Li, Y. Wang, et al., "Performances of Al 20 3/SiC hybrid nanofluids in minimum-quantity lubrication grinding," The International Journal of Advanced Manufacturing Technology, vol. 86, pp. 3427-3441, 2016.

29. N. Ahammed, L. G. Asirvatham, and S. Wongwises, "Entropy generation analysis of graphenealumina hybrid nanofluid in multiport minichannel heat exchanger coupled with thermoelectric cooler," International Journal of Heat and Mass Transfer, vol. 103, pp. 1084-1097, 2016.

30. Y. Zhang, C. Li, D. Jia, D. Zhang, and X. Zhang, "Experimental evaluation of the lubrication performance of MoS2/CNT nanofluid for minimal quantity lubrication in Ni-based alloy grinding," International Journal of Machine Tools and Manufacture, vol. 99, pp. 19-33, 2015.

31. S. M. Abbasi, A. Rashidi, A. Nemati, and K. Arzani, "The effect of functionalisation method on the stability and the thermal conductivity of nanofluid hybrids of carbon nanotubes/gamma alumina," Ceramics International, vol. 39, pp. 3885-3891, 2013. 
32. K. Kanthavel, K. Sumesh, and P. Saravanakumar, "Study of tribological properties on Al/Al203/MoS2 hybrid composite processed by powder metallurgy," Alexandria Engineering Journal, vol. 55, pp. 1317, 2016.

33. S. Khandekar, M. R. Sankar, V. Agnihotri, and J. Ramkumar, "Nano-cutting fluid for enhancement of metal cutting performance," Materials and Manufacturing Processes, vol. 27, pp. 963-967, 2012.

34. D. Wasan, A. Nikolov, and K. Kondiparty, "The wetting and spreading of nanofluids on solids: Role of the structural disjoining pressure," Current Opinion in Colloid \& Interface Science, vol. 16, pp. 344-349, 2011.

35. J. A. Ghani, C. H. C. Haron, S. H. Hamdan, A. Y. M. Said, and S. H. Tomadi, "Failure mode analysis of carbide cutting tools used for machining titanium alloy," Ceramics International, vol. 39, pp. 44494456, 2013.

36. R. K. Singh, A. K. Sharma, A. R. Dixit, A. K. Tiwari, A. Pramanik, and A. Mandal, "Performance evaluation of alumina-graphene hybrid nano-cutting fluid in hard turning," Journal of cleaner production, vol. 162, pp. 830-845, 2017.

37. E. Sadeghinezhad, M. Mehrali, S. Tahan Latibari, M. Mehrali, S. Kazi, C. S. Oon, et al., "Experimental investigation of convective heat transfer using graphene nanoplatelet based nanofluids under turbulent flow conditions," Industrial \& Engineering Chemistry Research, vol. 53, pp. 12455-12465, 2014.

38. W. Dai, B. Kheireddin, H. Gao, and H. Liang, "Roles of nanoparticles in oil lubrication," Tribology International, vol. 102, pp. 88-98, 2016.

\section{Figures}



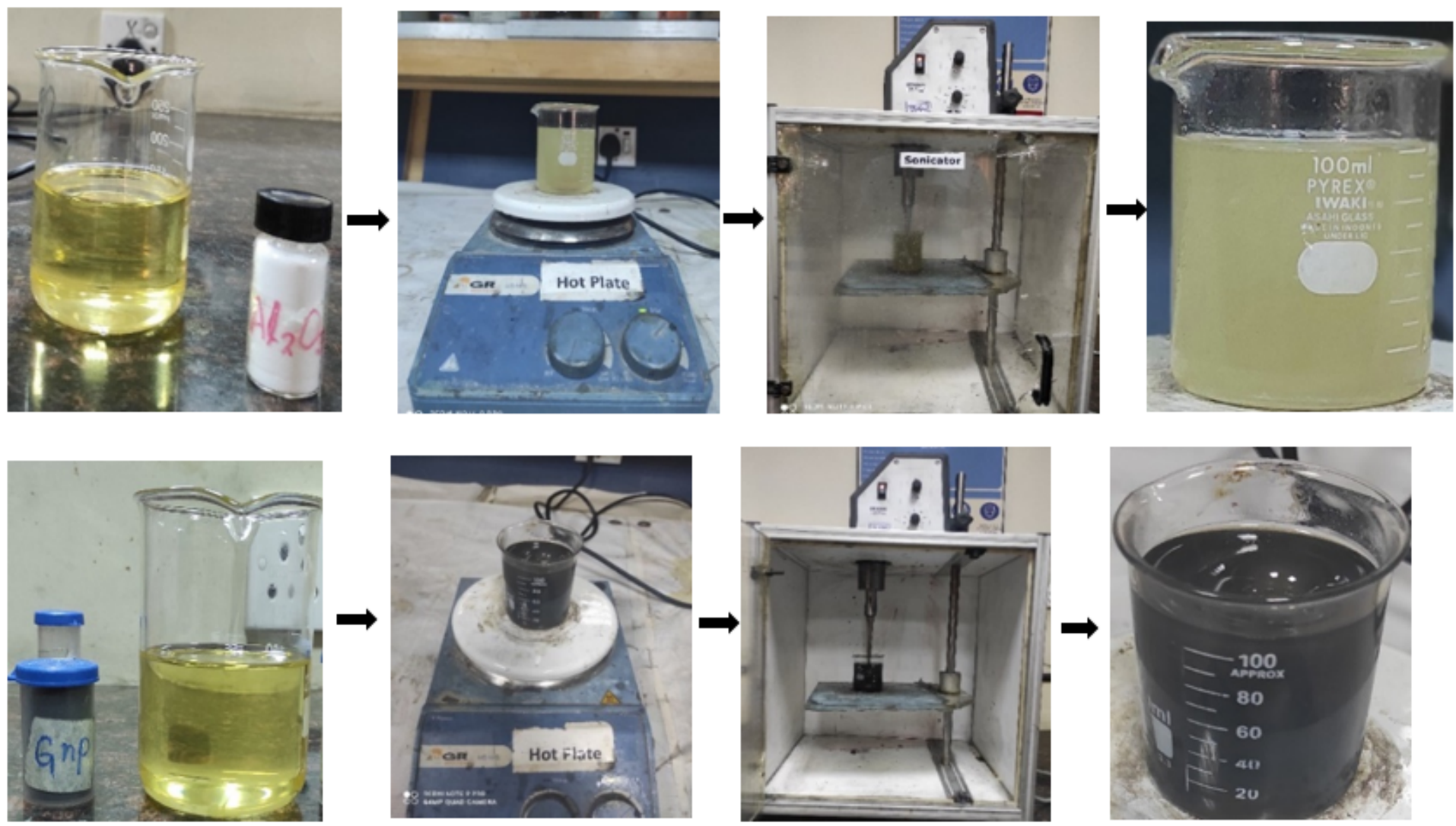

Figure 1

Al203 and Graphene bases nanofluids preparation

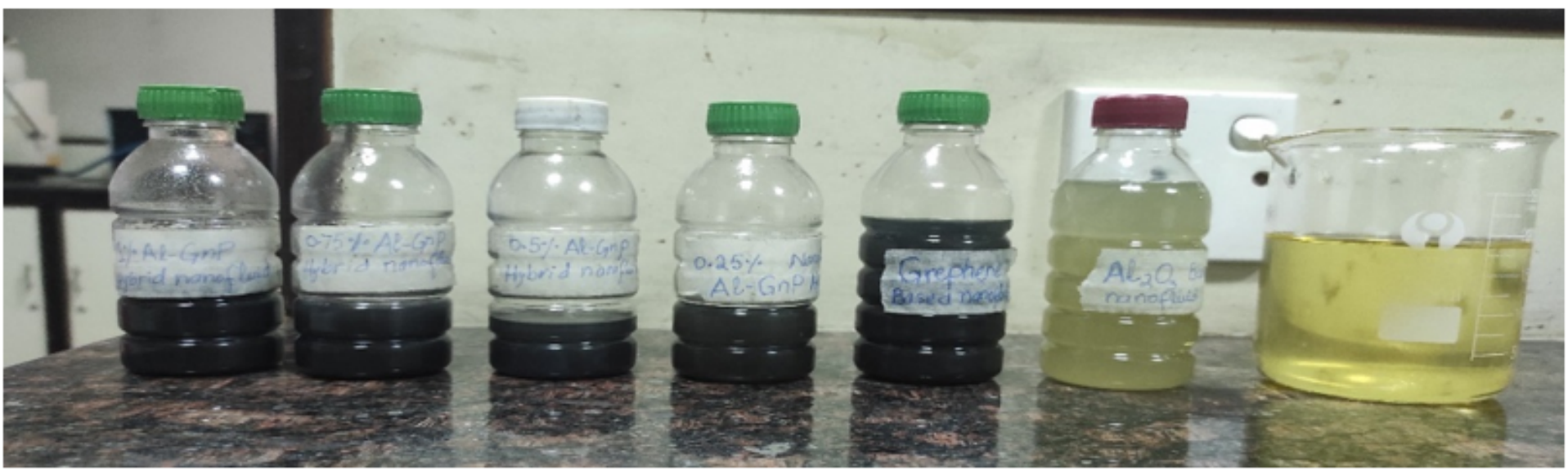

Figure 2

Nanofluids used in Machining Process 

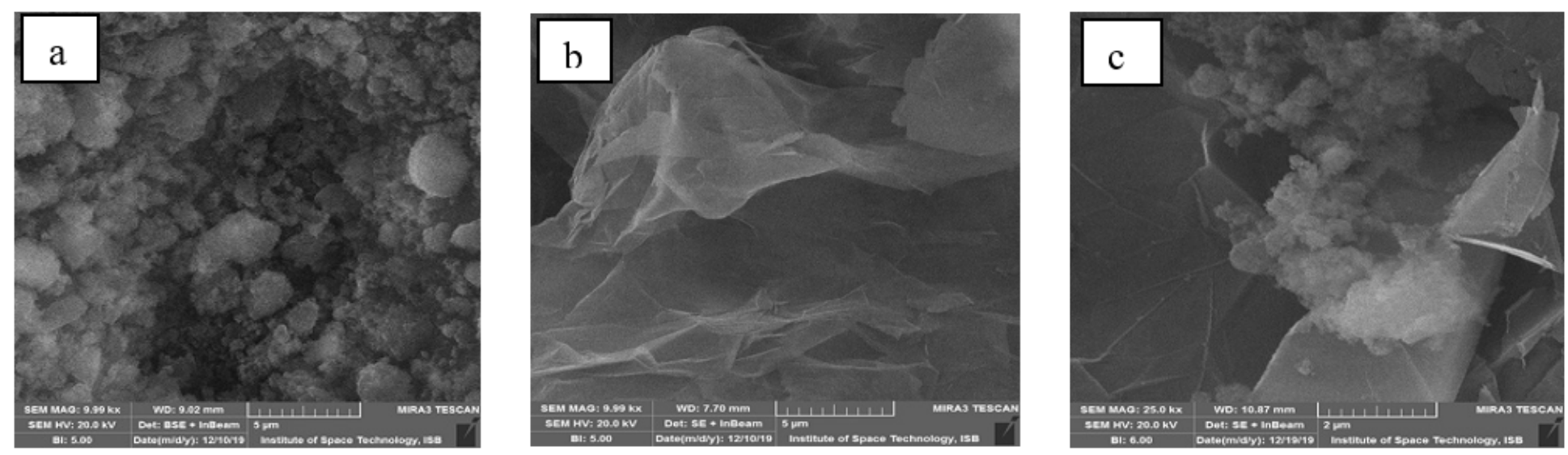

\section{Figure 3}

SEM Images of (a) Al2O3 nanoparticles (b) Graphene nano particles (c) Al-GnP hybrid nano particles

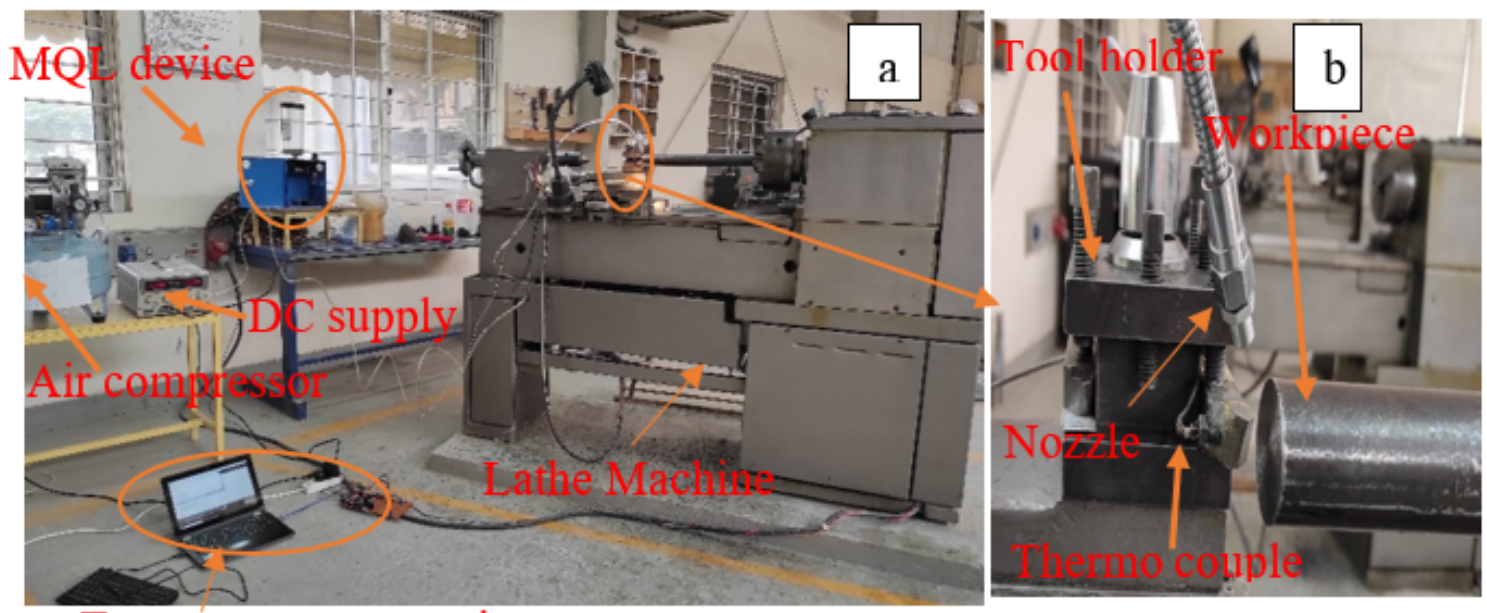

Temperature measuring system
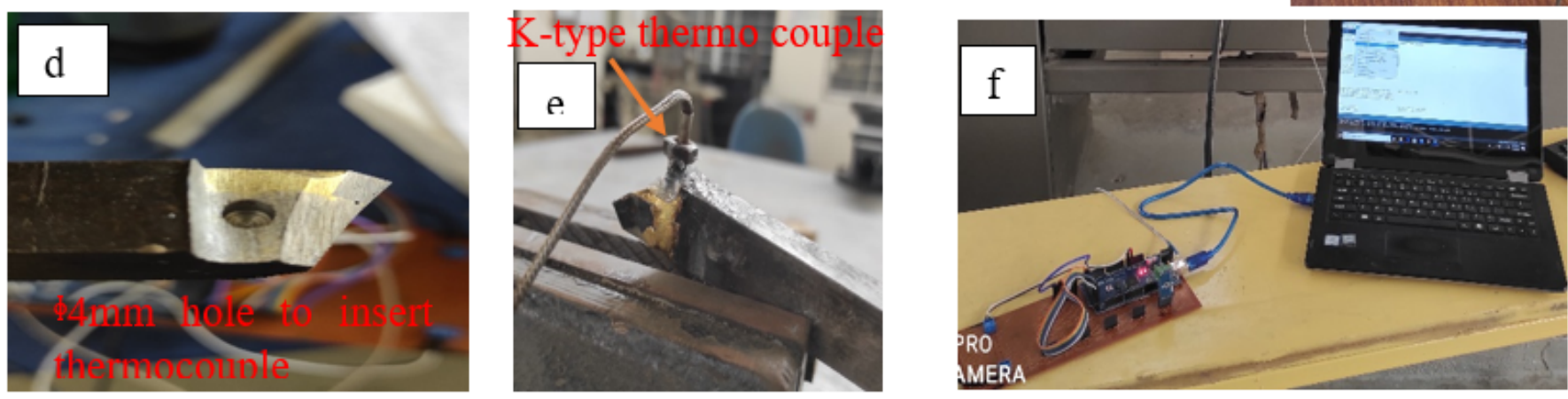

\section{Figure 4}

(a) pictorial view of experimental set up (b) closed view of machining zone (c) MQL system (d) carbide insert holder with drilled hole (e) Tool fitted with K type thermocouple (f) Temperature measuring system 

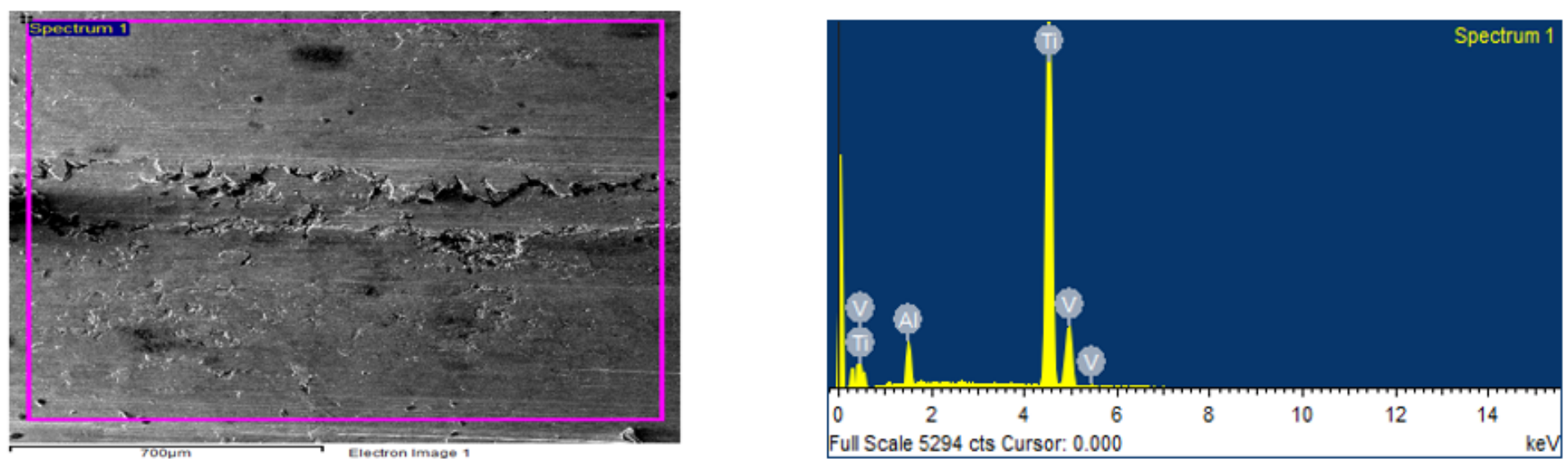

Figure 5

Workpiece Material 

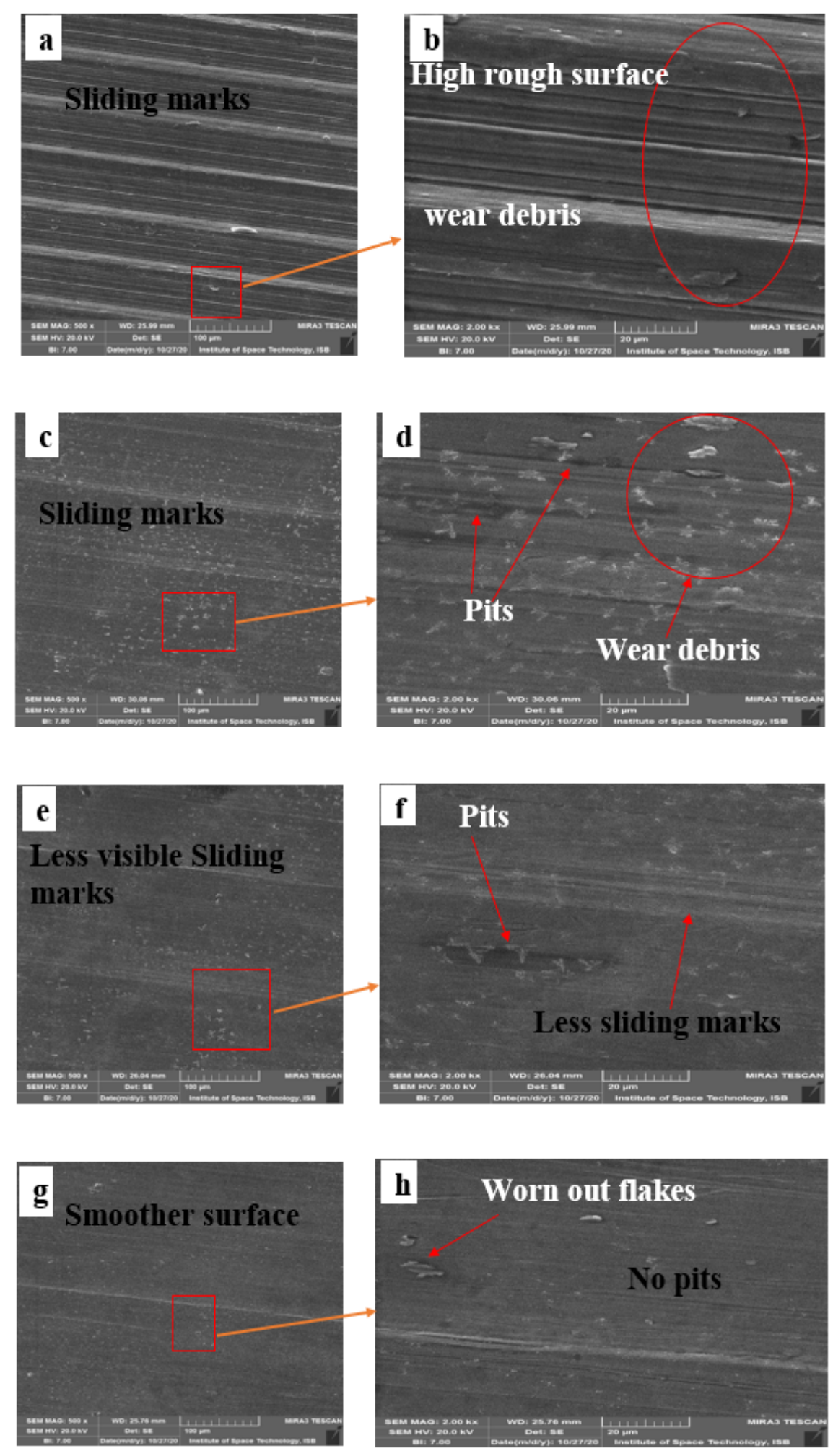

\section{Figure 6}

SEM images of work piece machined surface under ( $a$ and $b$ ) dry ( $c$ and d) base fluid (e and f) Al2O3 (g and h) Al2O3-graphene nanofluids in turning operation 

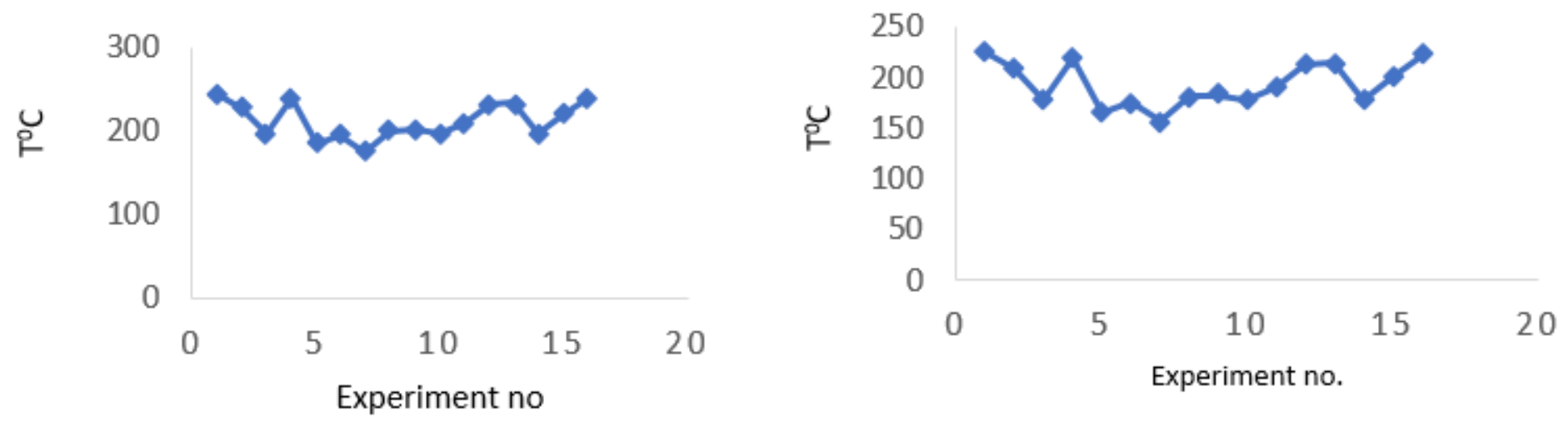

Figure 7

Measurement of milling Temperature (a) Alumina Based (b) Al-GnP hybrid nanofluid
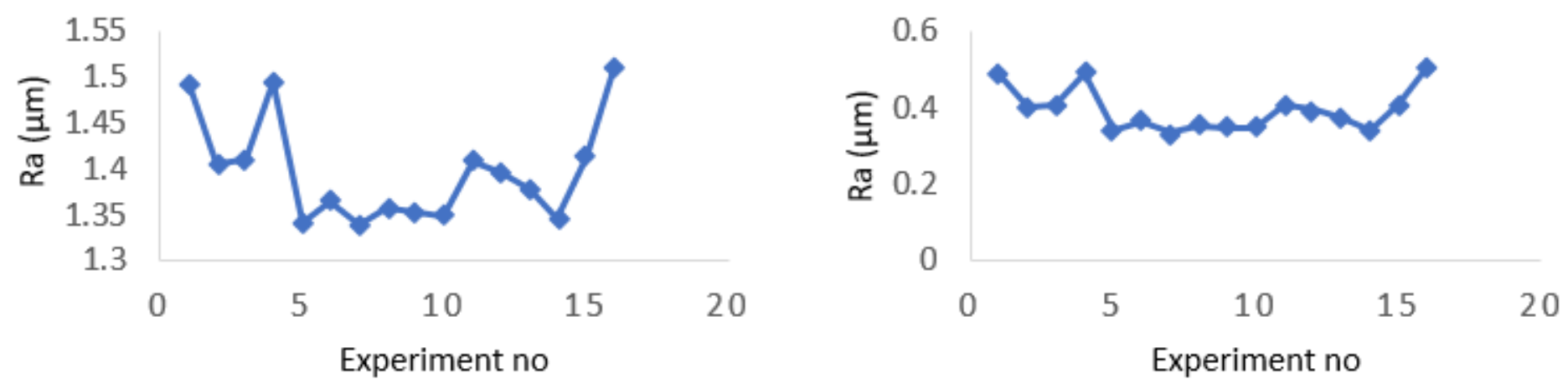

Figure 8

Measurements of surface roughness (a) Al302 based nanofluid (b) Al-GnP hybrid nanofluid 